Res Pública Revista de Historia de las Ideas Políticas

ISSN: 1131-558X

\title{
P. Filigrana, El pueblo gitano contra el sistema-mundo, Madrid, Akal, 2020, 156
} pp.

El sistema mundo. Esta obra pretende reparar una de las mayores injusticias de la historia, el antigitanismo. A pesar de los estereotipos, el pueblo gitano guarda el potencial de inspirar a los payos en sus intentos por dar con alternativas al actual sistema-mundo que se sustenta sobre la explotación de dos tercios de la humanidad. Podría para ello ir más allá, expresándose de manera distinta a como se hace en la academia, pero de momento el ensayo científico es lo más conveniente dado que se hace más comprensible a la cultura paya actual.

El modelo económico imperante no tiene un afuera. El capitalismo ha cubierto la tierra entera, sin dar optativas para aquellos que no quieran salirse del mismo. El resultado es la explotación de millones de seres humanos que no han escogido esta forma de vida, pero que no tienen otra opción, advocados a una vida de trabajo sin remuneración adecuada, o a rellenar las cifras del desempleo, situación que ni siquiera garantiza la vida.

Esta situación de desigualdad se refuerza cuando cierta parte de la humanidad se ve empujada a ocupar la parte más desfavorable de las relaciones económicas actuales por motivos de género, raza o nacionalidad. Situación que se ve naturalizada por la teoría económica imperante, que considera que el intercambio de bienes buscando priorizar la ganancia es el único modelo económico posible, dado que parte de la naturaleza humana.

El primer paso para para combatir este sistema de muerte es desnaturalizarlo, erradicar la subjetividad moderna occidental que no es capaz de ver más allá. En cambio, la visión de las comunidades que han quedado a los márgenes de este sistema-mundo es crucial para mantener la esperanza por un cambio. Estas comunidades, como es el caso del pueblo gitano, nos recuerdan que la riqueza siempre se crea a través de la cooperación. Por ello, los payos interesados en poner en cuestionamiento el orden de cosas actual, debería tener en el pueblo gitano un referente.

El pueblo gitano contra el sistema mundo. El pueblo gitano se ha negado a participar del orden económico capitalista al rechazar vender su fuerza de trabajo a cambio de un salario. El resultado ha sido la represión. Desde el intento de expulsión por parte de los Reyes Católicos en 1499 , las instituciones españolas han promulgado multitud de leyes antigitanas. El objetivo ha sido eliminar la disidencia gitana, tratando de doblegar a los gitanos haciéndoles entender que no tienen cabida fuera del orden impuesto. Si bien hasta ahora el estado español no ha logrado su objetivo, siglos de persecución han termina- do por apuntalar una serie de estereotipos negativos muy dañinos para los gitanos en el imaginario colectivo payo.

La supuesta vagancia de los gitanos es, quizás, uno de los estereotipos más extendidos acerca de ellos. Precisamente hay un interés en asociar a la comunidad gitana con la animadversión al trabajo, dado que esta ofrecía resistencia a la regularización y control de su economía por parte de ciertos sectores económicos y políticos. Lo cierto es que los gitanos han trabajado para obtener su sustento, como todo grupo humano, destacando en profesiones como canasteros, herreros o músicos. El problema ha sido la imposibilidad de forzarles a trabajar de la manera que el poder payo buscaba, el cual lo ha intentado por todos modos, incluyendo la violencia.

Las instituciones españolas trataron que los gitanos abandonasen su modo de vida durante siglos, forzándoles a asentarse allí donde fuese conveniente, y a trabajar como siervos o como asalariados. Pero las dificultades para lograr que obedeciesen llevó numerosas veces a condenarles a trabajos forzados. Esto ha sucedido de un modo u otro a lo largo de la historia, pero hay un caso particularmente vergonzoso en la historia española, la Gran Redada.

El 28 de junio de 1749, durante el gobierno de Fernando VI, se dio la orden de apresar a todos los gitanos del país. La intención era deshacer la comunidad gitana separando por un lado a hombres adultos, y a mujeres y niños por otro. A los primeros se les condenó a trabajos forzados, principalmente a galeras y minas, a los segundos se les encerró en presidios y casas de misericordia, donde además de darles trabajo se intentó forzarles a abandonar sus elementos culturales. La idea era impedir que los gitanos tuviesen descendencia, de ahí que se separase a mujeres y hombres. El trabajo forzado y la confiscación de bienes financiaría la operación. Afortunadamente, la mala organización de las instituciones españolas, y la resistencia de los gitanos, en especial la de las gitanas, a obedecer los mandatos racistas, pusieron término a uno de los acontecimientos más vergonzosos del país, y las autoridades dieron marcha atrás en el proyecto.

Estas medidas, como con toda la legislación antigitana, constituyen una auténtica ley de extranjería. Declaraba a la comunidad calé como no autóctona, y pretendía forzarla a cambiar para adaptarse a la mentalidad local, $\mathrm{o}$, en su defecto, a convertirla en trabajadores útiles para el sistema por medio del castigo. Aquí hay un claro paralelismo con la comunidad inmigrante a día de hoy en el estado español. Esta sólo es aceptada si se ajusta a las 
necesidades del mercado laboral por medio de un contrato de trabajo. En caso de no contar con este, al inmigrante se le declara ilegal, y se ve en una circunstancia de excepción por la que se le convierte en una completa otredad, por lo que se le da un trato diferenciado y discriminatorio del resto de la sociedad. Esta situación deja en un limbo legal a los inmigrantes indocumentados, que se ven forzados a trabajar bajo el chantaje de la expulsión en condiciones más duras que el resto.

Tanto en el caso gitano como en el de los inmigrantes irregulares actuales se da una paradoja similar. Las instituciones españolas les muestran hostilidad, pero no tienen un verdadero interés por acabar con ninguna de ellas. Ni se buscaba la erradicación completa de los gitanos en su momento, ni la expulsión total de los inmigrantes ahora. Por el contrario, el objetivo ha sido dejar a ambas comunidades en un limbo ontológico, por el cual se les convierte en algo diferenciado del resto de la sociedad, con unas características particulares que justifican su explotación laboral.

Para evitar confrontar la responsabilidad de la España blanca en los planes de erradicación de los gitanos, se ha establecido la creencia de que los gitanos no se quieren integrar. Es una estrategia para culpabilizar a los gitanos de las desavenencias con los payos. Como parte de este discurso se ha negado que los gitanos sean una cultura diferenciada, por lo que no tienen justificado un modo de vida distinto de la del resto del país. Esta creencia colabora de los esfuerzos por generar una sociedad homogénea amoldada al orden económico y social imperante. Fue promovida por el gobierno de Carlos III, quien en el 1783 promulgó una pragmática por la cual se negaba la diferencia de los gitanos como cultura autónoma, y se les exigía el abandono de las costumbres que les diferenciaban como tal.

Como parte de esa persecución de la diferencia gitana, sus bailes y músicas quedaron prohibidas. La tradición musical gitana ha sido una de las señas de la comunidad desde su llegada a España, y uno de los principales objetivos de prohibición por parte de las autoridades del país. De nuevo la paradoja se aprecia cuando las mismas autoridades, incluyendo a monarcas, han gozado habitualmente de espectáculos de danza representados por gitanos. Más aún, estas tradiciones musicales, englobadas con el término flamenco, han sido objeto de interés por parte de la sociedad paya, que siempre ha mantenido una relación de amor y odio con los gitanos, sus manifestaciones culturales y su expresividad. La "gracia" gitana ha sido y es objeto de controversias. Su mayor expresión, el arte flamenco, ha sido interpretado infinidad de veces por los académicos payos, que tienen dificultades para reconocer la autoría gitana de la tradición, cometiendo una forma más de agresión hacia los calés, la apropiación cultural.

Desposeídos de cultura propia, los gitanos son acusados de los más viles males posibles. La comunidad padece el estereotipo de violenta y patriarcal. No acuden a las autoridades para resolver sus conflictos, lo que se traduce en peleas entre familias que acaban en episodios violentos, y recortan la libertad de las mujeres.
Pero quien los acusa de ello desconoce que el pueblo gitano cuenta con sus propias autoridades que gestionan los conflictos. Esta circunstancia es otro elemento más que mantiene al pueblo gitano independiente de unas instituciones payas que han ejercido históricamente la violencia contra la comunidad, sin dar soluciones a sus problemas, y provocándoselos en cambio. En cuanto a la acusación de patriarcales no tiene sentido verdadero, dado que el patriarcado es la forma de opresión de género aparecida en el mundo blanco, por lo que es ajena al resto de los pueblos. Esto no quiere decir que no haya opresión de género en el resto de sociedades, simplemente que el patriarcado es la forma de opresión de hombre a mujer genuinamente occidental. En el resto del mundo se han generado casos de opresión de género, pero no son el patriarcado propiamente. A día de hoy es posible encontrar patriarcado fuera de la esfera occidental, pero es fruto de la colonización, como pueda suceder con la comunidad gitana. El feminismo romaní precisamente busca la liberación de la mujer gitana de los elementos patriarcales que le ha sido impuesta a su comunidad por el poder payo.

Trabajar con lo fragmentado: la propuesta. Aquellos que llevan su vida en los márgenes del sistema imperante soportan una continua amenaza por ello. Muchas son las personas que, por un motivo o por otro tienen razones para rechazar el modelo de vida actual. Los continuos esfuerzos para llevar a cabo una oposición al orden imperante han fracasado. En su mayoría se han aglutinado bajo el paraguas del movimiento obrero, vertebrado principalmente por el marxismo.

Todas aquellas personas que tienen que trabajar para vivir tienen intereses comunes, dado que todas se ven advocadas o a participar con su trabajo de un orden económico concreto, o, a operar a los márgenes del sistema, por lo que se ven castigadas por ello. Sin embargo, no todas ellas padecen el estatus quo de igual manera. Hay una jerarquía de identidades sustentadas en la realidad particular de cada cual, en base a género, raza, clase, orientación sexual y otros aspectos que determinan la experiencia que cada persona tiene en esta vida. El problema viene cuando ciertos sectores, partícipes de una identidad común, rechazan la diversidad de otros menos favorecidos, y rechazan tener en cuenta sus aspiraciones. En particular, los movimientos sociales que provienen de la comunidad blanca, ya sean obreristas, feministas u otros, no están teniendo en cuenta la diferencia de las personas que han sufrido la colonización. De esta manera participan de la opresión a estas comunidades, y las impiden aportar a la lucha frente a esa opresión.

Por ello es fundamental tomar consciencia del lugar que se ocupa en la jerarquía de humanidades establecida por la alianza capitalismo-patriarcado-racismo, para entender nuestro punto de partida en la lucha por la igualdad. Sólo a partir de aquí podremos empezar a interesarnos por las formas de resistencia que se generan en los márgenes, de las que tenemos que aprender estrategias para oponernos al orden de muerte imperante.

Ignacio Marcial Ercilla 